\title{
Preliminary Phytochemical Analysis and in Vitro Antioxidant Activity of Boscia arabica Leaves
}

\author{
Saleh Kassem Algfri*, Ammar Ali Qaid, Sumaia Ahmed Mahde \\ Department of Pharmacognosy, Faculty of Pharmacy, University of Aden, Aden city, Yemen.
}

*Corresponding author's E-mail: algfri_s25@yahoo.com

Received: 18-02-2021; Revised: 25-04-2021; Accepted: 30-04-2021; Published on: 15-05-2021. \begin{abstract}
Boscia arabica (Capparaceae), popularly known as "Sarh", is a plant utilized in Yemen in traditional medicine for treatment of many ailments, but very few studies have been carried out on this plant. The Boscia arabica leaves were selected to phytochemical analysis and evaluate antioxidant activity. Physico-chemical parameters of leaves powder were established and are within the acceptable ranges. The leaves powder was treated with various reagents and the mixture was observed under day light and under UV light to see the type of fluorescence. Different fluorescence colours were observed. Chemical analysis was carried out to determine the major chemical classes, phytoconstituents like carbohydrates, saponins, flavonoids, triterpenes, sterols and alkaloids were identified in studied extracts. The presence of phytoconstituents was further confirmed by thin layer chromatography and Rf values of developed spots were calculated with color intensity. Antioxidant activity of Boscia arabica leaf extracts was carried out via DPPH staining technique. The result of dot-blot assay showed yellow-coloured spots when stained with DPPH solution. The free radical scavenging activity of $80 \%$ methanol extract and it's fractions was determined and antioxidants activity ranged from (14.81 \pm 3.22$)$ for methanol $80 \%$ extract to $(85.31 \pm 3.12)$ for $n$-butanol fraction. Ethyl acetate $(84.30 \pm 2.44)$ and $n$-butanol $(85.31 \pm 3.12)$ are exhibited high free radical scavenging activity when compared with quercetin (99.10 \pm 4.22 ). The results obtained in this study support the use of Boscia arabica in traditional medicine, which may be a promising source for the development of natural antioxidants.
\end{abstract}

Keywords: Boscia arabica, Yemen, phytochemical, antioxidant.

QUICK RESPONSE CODE $\rightarrow$

DOI:

10.47583/ijpsrr.2021.v68i01.022

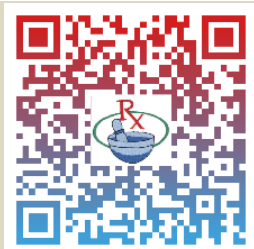

DOI link: http://dx.doi.org/10.47583/ijpsrr.2021.v68i01.022

\section{INTRODUCTION}

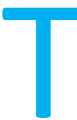

he study of medicinal plants is one of the most important topics of interest to researchers in Yemen.

The traditional medicinal methods still play a vital role in the prevention, diagnosis and treatment of illness in Yemen, and most of the medicinal substances are plantbased, a reflection of the country's rich vegetation ${ }^{1}$. To date, only few medicinal plants have been studied ${ }^{2}$, Therefore, there is a need to evaluate phytoconstituents obtained from traditional medicines, based on various phytochemical screening and pharmacological and analytical methods ${ }^{3}$. According to World Health Organization (WHO) pharmacognostic parameters are necessary for confirmation of the identity and determination of quality and purity of a crude drug used in traditional medicine ${ }^{4}$. The plant kingdom is a wide range of natural antioxidants. In the category of secondary plant metabolites, antioxidant phenolics are commonly found in plants and they have indicated providing a defense against oxidative stress ${ }^{5,6}$.
The genus Boscia (Capparaceae) contains more than 37 species distributed mainly in Africa, excluding one species found in southern Arabia7. Boscia arabica Pestalozii is endemic to Arabian Peninsula and is found only in Yemen and Saudi Arabia ${ }^{8}$. It is used by Yemeni people in traditional medicine for treatment of many diseases including kidney disease. Up to date, no pharmacognostic, phytochemical or pharmacological studies have been reported for this plant. The leaves of Boscia arabica were selected with the aim of phytochemical analysis and evaluation of antioxidant activity. The present study is an essential step and requires long-term phytochemical and pharmacological studies.

\section{MATERIALS AND METHODS}

\section{Plant material}

The fresh leaves of Boscia arabica pestalozzi were collected in July 2018 from Abyan, Republic of Yemen, dried in the shaded area and then manually grinded and stored at room temperature for further analysis. The plant sample was identified by a taxonomist, Associate Professor Othman S. Alhawshabi, of the faculty of Science, University of Aden, Yemen.

\section{Physicochemical analysis}

The physicochemical parameters such as loss on drying, total ash, acid insoluble ash, water soluble ash, water soluble extractive and ethanol soluble extractive were carried out in dried leaves powder according to standard methods ${ }^{9,10}$. 


\section{Fluorescence analysis of powdered drug}

A fine powder of studied leaves was placed on a grease free clean microscopic slide and added 1-2 drops of the freshly prepared reagent solutions mixed properly and waited for 1-2 minutes. Then the slide was viewed in day light and inside the UV viewer chamber short ( $254 \mathrm{~nm}$ ) and long $(365 \mathrm{~nm}$ ) ultraviolet radiations. The colors observed by application of different reagents in different radiations were recorded ${ }^{11}$.

\section{Preparation of extracts}

The dried powdered leaves (50 gm) were defatted with petroleum ether (boiling point $60-80{ }^{\circ} \mathrm{C}$ ) in soxhlet extractor. The marc left after petroleum ether extraction was dried completely in hot air oven below $50^{\circ} \mathrm{C}$ and then packed well in soxhlet apparatus and extracted with $80 \%$ methanol $\left(80-90^{\circ} \mathrm{C}\right)$, until the extraction was completed. The marc after that was dried and extracted with sterilized water. Resulting extracts in different solvents were evaporated and concentrated to dryness using the rotary evaporator at $50^{\circ} \mathrm{C}$ and the percentage yield in terms of air dried material was calculated. The dry extracts were used for further analysis ${ }^{12,13}$.

\section{Fractionation of $80 \%$ methanol extract}

Fractionation of $80 \%$ methanol extract was carried out with different organic solvents. Methanol (80\%) extract was suspended in water, extracted successively with chloroform, ethyl acetate and $\mathrm{n}$ butanol $(6 \times 300 \mathrm{ml}$ each) and then resulting solutions were concentrated to provide chloroform, ethyl acetate, $\mathrm{n}$ butanol and water residue fractions. The rest of methanolic extract (20\%) was used for further phytochemical analysis ${ }^{13}$.

\section{Qualitative phytochemical analysis}

Preliminary analysis of $80 \%$ methanol and water extracts was carried out to identify the presence of various phytoconstituents by

employing standard protocols ${ }^{13,14}$.

\section{Thin layer chromatography studies}

Thin Layer Chromatography of prepared extracts was performed to determine Rf values. Various solvent systems were tested to obtain best results. TLC plates were first viewed in day light then in UV chamber before keeping in iodine chamber and Rf of all were noted. Different solvent systems were found to be effective to get maximum no. of spots for various extracts ${ }^{15,16}$.

\section{Antioxidant studies}

\section{Rapid screening of antioxidant by dot-blot and DPPH staining}

Each diluted sample of the extracts/fractions was carefully loaded onto a $20 \mathrm{~cm} \times 20 \mathrm{~cm}$ TLC layer (silica gel 60 F254; Merck) and allowed to dry (3 $\mathrm{min})$. Drops of each sample were loaded, in order of decreasing concentration $(0.5$, 0.25 and $0.125 \mathrm{mg} / \mathrm{mL}$ ), along the row. The staining of the silica plate was based on the procedure. The sheet bearing the dry spots was placed upside down for $10 \mathrm{~s}$ in a $0.05 \%$ 2, 2-diphenyl-1-picrylhydrazyl (DPPH) solution. Then the excess of solution was removed with a tissue paper and the layer was dried with a hair-dryer blowing cold air. Stained silica layer revealed a purple background with yellow spots at the location where radical-scavenger capacity presented. The intensity of the yellow color depends upon the amount and nature of radical scavenger present in the sample ${ }^{17}$.

\section{DPPH Radical Scavenging Activity}

The scavenging activity for DPPH free radicals was measured according to the procedure described by the Braca et al., with some modifications ${ }^{18}$. In the assay, the DPPH reagent was prepared by dissolving the $0.04 \mathrm{~g}$ DPPH in $100 \mathrm{ml}$ of methanol. From this stock $3 \mathrm{ml}$ of DPPH solution in methanol and $0.1 \mathrm{ml}$ of plant extract at various concentrations or fractions $(50-250 \mu \mathrm{g} / \mathrm{ml})$ were mixed. The mixtures vortexed and allowed for $30 \mathrm{~min}$ to reach a steady state at room temperature. Decolonization of DPPH was determined by measuring the absorbance at $517 \mathrm{~nm}$. A control was prepared using $0.1 \mathrm{ml}$ of respective vehicle in the place of plant extract.

The percentage inhibition activity was calculated as extract/ascorbic acid.

$$
\text { Inhibitory ratio }=(A 0-A 1) / A_{0} \times 100
$$

Where, A0 is the absorbance of control (quercetin); $A 1$ is the absorbance of the plant extract.

\section{IC50 value}

Inhibition Concentration (IC50) parameter was used ${ }^{19}$, for the interpretation of the results from DPPH method. The discoloration of sample was plotted against the sample concentration in order to calculate the IC50 value. It is defined as the amount of sample necessary to decrease the absorbance of DPPH by $50 \%$.

\section{RESULTS AND DISCUSSION}

\section{Physicochemical analysis}

In accordance with WHO guidelines, it is important to evaluate the physicochemical and phytochemical characters of crude drug for developing standardized quality control profile of herbal medicine ${ }^{10,20}$. In the present study, various parameters like ash content, solvent extractive values, moisture, were estimated for Boscia arabica leaves and are within the acceptable ranges. The results obtained were described in Table 1. Ash values are important quantitative standards used to find out quality, identity and purity of crude drugs especially in the powder form $^{21,22}$. The extractive value gives an idea about the nature of the chemical constituents present in a crude drug and furthermore assist in the evaluation of definite constituents soluble in a particular solvent ${ }^{23,24}$. Excess of water content in plant materials results in microbial growth and deterioration, so determination of moisture content is another important parameter that should be evaluated for plant drugs ${ }^{25}$. Dried herbal drug is expected

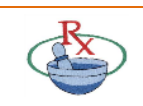


to have a long shelf-life with reduced chance of microbial growth due to its relatively low moisture content ${ }^{26}$.

\section{Fluorescence analysis of powdered drug}

Fluorescence study powdered drug under ultra violet light is very distinctive and helpful in establishing the purity of the drug ${ }^{27}$. The fluorescence analysis of the powder drug was done. The powder of studied leaves was treated with various reagents and the mixture was observed under day light and under UV light to see the type of fluorescence. The results are given in Table 2 .
Table 1: Physico-chemical parameter of leaves of Boscia arabica leaves

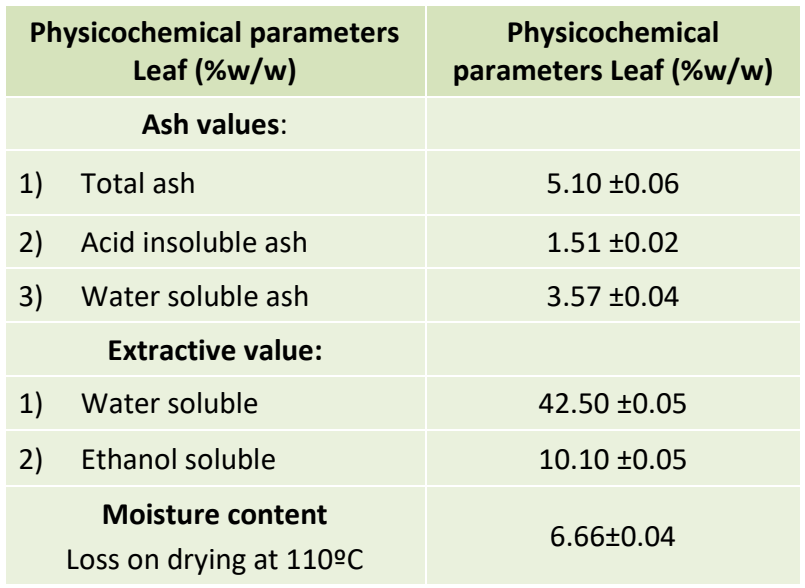

Table 2: Fluorescence analysis of powdered Boscia arabica leaves.

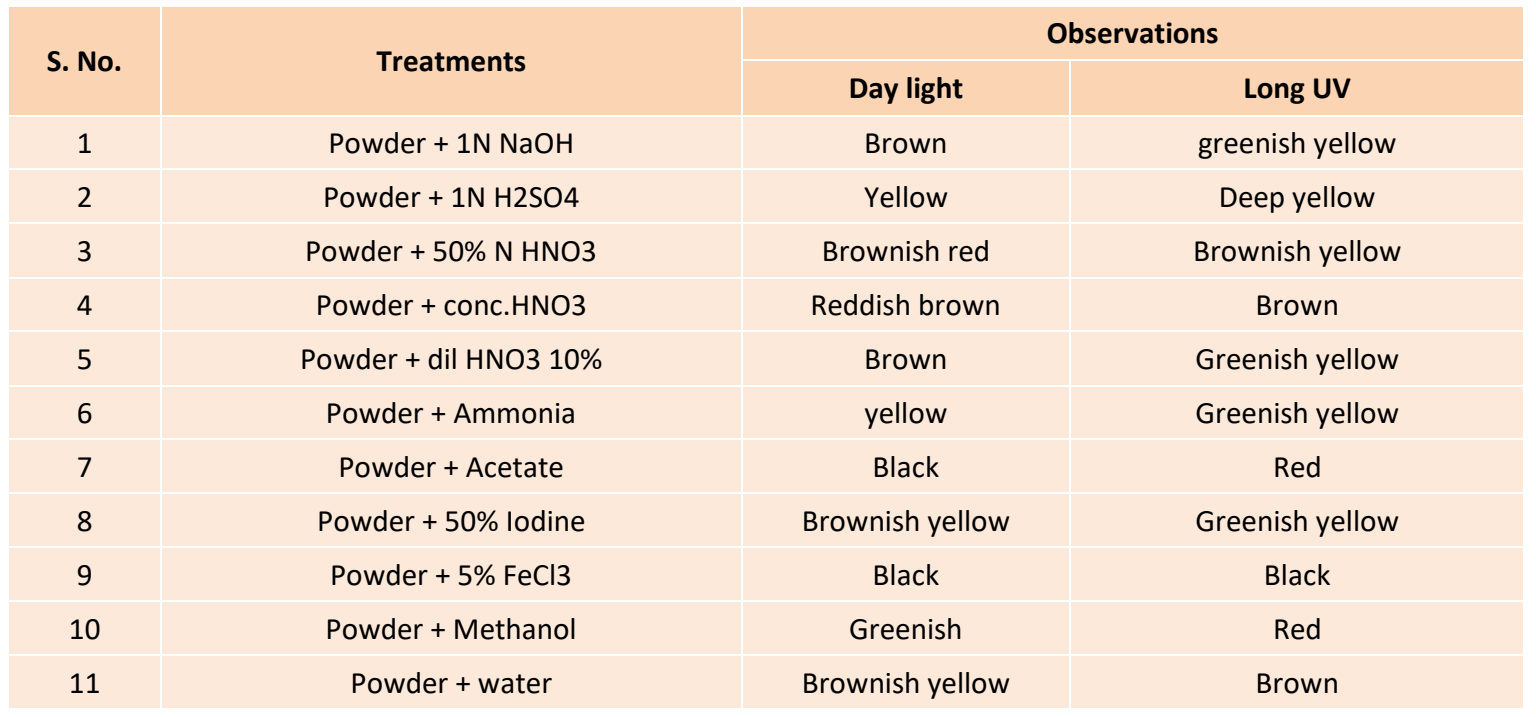

\section{Preliminary phytochemical screening}

The percentage yield of petroleum ether, methanol $80 \%$ and water extracts of the leaves powder of Boscia arabica were determined and the result shown in the Table 3. Phytochemical screening of the methanol $80 \%$ and water extracts was done and results were represented in Table 4. Phytoconstituets like carbohydrates, saponins, polyphenols, flavonoids, tannins, triterpenes, sterols and alkaloids were identified in studied extracts. Identification of the different classes of phytochemical constituents of the plant is an important parameter which gives an indication of the pharmacological active metabolites present in that plant ${ }^{28}$. Secondary metabolites of plants are reported to have many biological and therapeutic properties ${ }^{29-31}$. The phenolic compounds have been reported to have anti-oxidants property due to their conjugated ring structures and the presence of hydroxyl groups $^{32,33}$, also they have been reported to exhibit cardioprotective, hepatoprotective, anti-allergenic, antiinflammatory, antimicrobial, antithrombotic, antiatherogenic, and vasodilatory effects ${ }^{34,35}$.

Table 3: The percentage yield of petroleum ether, methanol and water extracts of the leaves of Boscia arabica

\begin{tabular}{|c|c|c|c|c|}
\hline S. No. & Solvent & $\begin{array}{c}\text { Weight of plant material } \\
\text { (gm) }\end{array}$ & $\begin{array}{c}\text { Percentage of Yield } \\
\text { (\%) }\end{array}$ & Colors of extracts \\
\hline 1 & Petroleum Ether & 50 & 1.50 & Green \\
\hline 2 & Methanol 80\% & 50 & 17.00 & Greenish brown \\
\hline 3 & Water & 50 & 40.60 & Reddish brown \\
\hline
\end{tabular}


Table 4: Results of phytochemical screenings of successive extracts of the leaves of Boscia arabica.

\begin{tabular}{|c|c|c|c|}
\hline \multicolumn{2}{|c|}{ Phytochemical Screening } & Methanol $80 \%$ extract & Water extract \\
\hline \multirow{3}{*}{ Alkaloids } & Wagner's test & +++ & ++ \\
\hline & Mayer's test & +++ & - \\
\hline & Dragendorff's reagent & +++ & - \\
\hline Polyphenols & Ferric chloride test & ++ & +++ \\
\hline \multirow{4}{*}{ Flavonoids } & Shinoda test & ++ & ++ \\
\hline & $\mathrm{NaOH}$ Test & +++ & +++ \\
\hline & Lead acetate test & ++ & ++ \\
\hline & Aluminium solution test & ++ & ++ \\
\hline Saponins & Foam test & ++ & +++ \\
\hline \multirow{2}{*}{ Sterols/ Triterpenes } & Salkowski test & +++ & +++ \\
\hline & Liebermann-Burchard test & +++ & +++ \\
\hline \multirow{2}{*}{ Carbohydrates } & Molisch's test & ++ & ++ \\
\hline & Fehling's test & ++ & + \\
\hline \multirow[t]{2}{*}{ Tannins } & Ferric chloride test & ++ & +++ \\
\hline & Gelatin test & - & - \\
\hline
\end{tabular}

$+++=$ Most intense,$++=$ moderately intense,$+=$ Least intense, $-=$ absent .

\section{Thin layer chromatography}

TLC is still the basic tool for the separation and identification of natural compounds. It is often used to provide the first characteristic fingerprints of herbs ${ }^{36}$. TLC (silica gel G 60 F254 TLC plates of layer thickness $0.2 \mathrm{~mm}$, Allugram- Germany) of prepared methanol $80 \%$ extract and chloroform, ethyl acetate, n-butanol and water fractions was performed. The best solvent systems was Chloroform - Methanol - Formic acid (44:3.5:2.5). Photos of the plates were taken in day light and in UV chamber and $R f$ values of developed spots of different extracts were calculated as well as the colour of spots were observed, which are mentioned in Table 5 and Figure 1.

Table 5: Observations of thin layer chromatographic of methanol $80 \%$ extract and its fractions of Boscia arabica leaves in Chloroform - Methanol - Formic acid (44:3.5:2.5)

\begin{tabular}{|c|c|c|c|c|c|}
\hline $\begin{array}{l}\text { Extract or } \\
\text { Fractions }\end{array}$ & $\begin{array}{l}\text { No. of } \\
\text { spots }\end{array}$ & Rf values & $\begin{array}{l}\text { Colour of the spot } \\
\text { in daily light }\end{array}$ & $\begin{array}{l}\text { Colour of the spot at } \\
\qquad 254 \mathrm{~nm}\end{array}$ & Colour of the spot at $365 \mathrm{~nm}$ \\
\hline \multirow{12}{*}{$\begin{array}{c}\text { Methanol } 80 \% \\
\text { extract }\end{array}$} & \multirow{12}{*}{12} & 6.5 & Light green & \multirow{12}{*}{ Quenching } & Red \\
\hline & & 6.1 & Not visible & & $\begin{array}{c}\text { white } \\
\text { fluorescent }\end{array}$ \\
\hline & & 5.9 & \multirow{4}{*}{ Green } & & Red \\
\hline & & 4.2 & & & Red orange \\
\hline & & 3.8 & & & Orange \\
\hline & & 6.3 & & & Orange \\
\hline & & 3.1 & \multirow{6}{*}{ Not visible } & & Blue fluorescent \\
\hline & & 2.7 & & & Orange \\
\hline & & 2.0 & & & Sky blue \\
\hline & & 1.4 & & & Sky blue \\
\hline & & 1.0 & & & Sky blue \\
\hline & & 0.8 & & & Sky blue \\
\hline \multirow{4}{*}{$\begin{array}{l}\text { Chloroform } \\
\text { fraction }\end{array}$} & \multirow{4}{*}{11} & 6.5 & Greenish brown & \multirow{4}{*}{ Quenching } & Red \\
\hline & & 6.1 & Green & & $\begin{array}{c}\text { white } \\
\text { fluorescent }\end{array}$ \\
\hline & & 4.2 & Dark & & Red \\
\hline & & 3.8 & Not visible & & Red \\
\hline
\end{tabular}




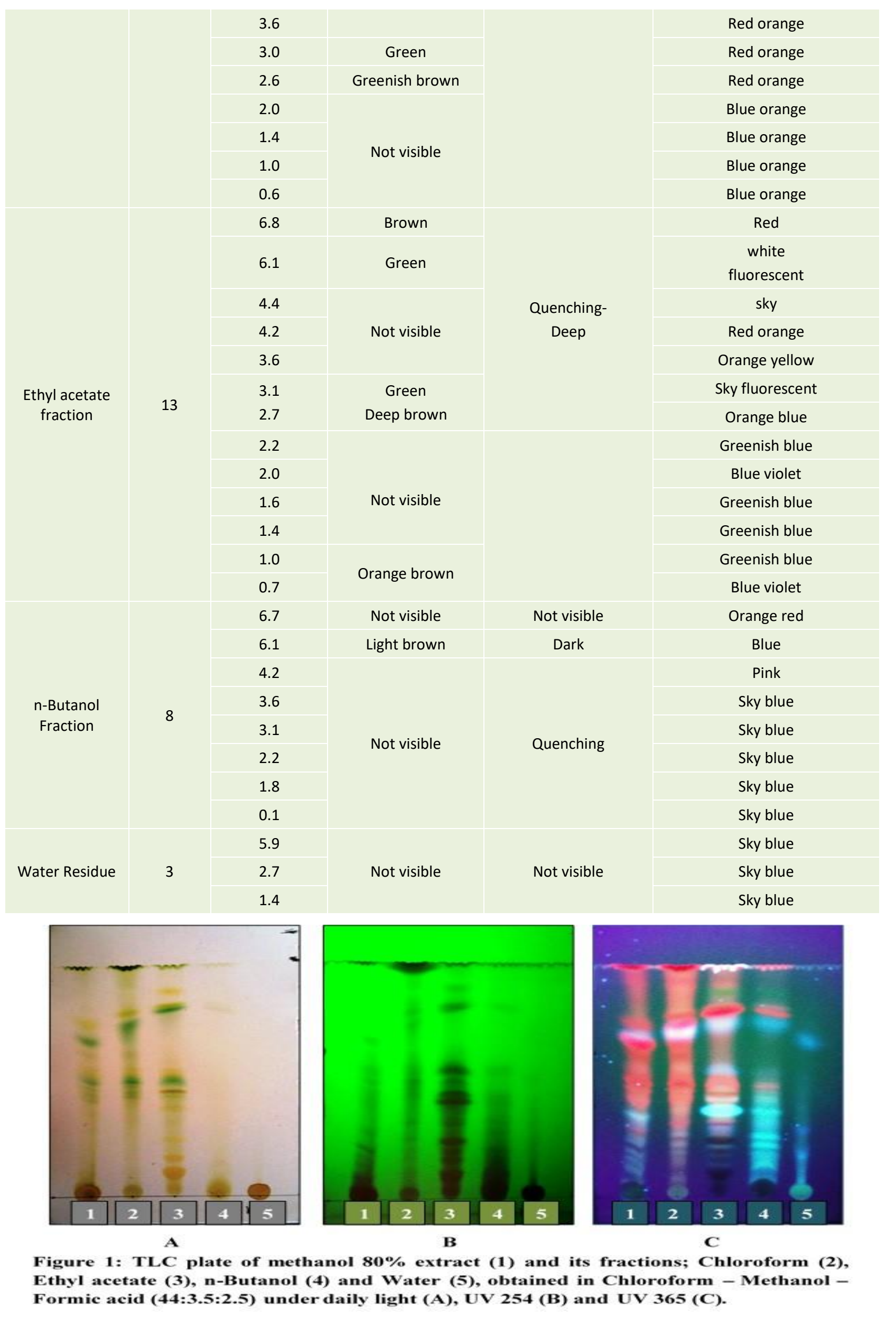




\section{Antioxidant studies}

Medicinal plants have been used for human healthcare and represent the mainstay of traditional systems of medicine. The importance of plants as natural sources of antioxidants and free radical scavengers has been reported earlier by various researchers ${ }^{35,37}$. Numerous methods to evaluate the antioxidant activity of specific compounds have been described, but the most widely documented relates to the 2, 2-diphenyl-1-picrylhydrazyl radical (DPPH), for fast and easy evaluation of the antioxidant activity due to its stability, reliability and the simplicity of the assay ${ }^{38-40}$. Compounds with antioxidant properties would change the purple color of DPPH to yellow as the radical is quenched by the antioxidant ${ }^{40}$. The antioxidant activity of Boscia arabica leaves was studied by the DPPH method.
Rapid screening of antioxidant by dot-blot and DPPH staining

The antioxidant potential activity of methanol $80 \%$ extract and its fractions was determined via eye-detected semiquantitatively via a rapid DPPH staining-TLC technique. The dot-blot test is an easy, fast and reliable way to compare radical scavenging capacity of various plant extracts ${ }^{41}$. Each diluted samples were applied as a dot on a TLC layer that was then stained with DPPH solution. Quercetin was used as a positive control. The results of dot-blot assay showed yellow colored spot when stained with DPPH solution (Figure 2). All dots at concentration of $0.5 \mathrm{mg} / \mathrm{ml}$, $0.25 \mathrm{mg} / \mathrm{ml}, 0.125 \mathrm{mg} / \mathrm{ml}$ and $0.0625 \mathrm{mg} / \mathrm{ml}$ showed high antioxidant activity when compared with control (quercetin), exception water fraction, which showed antioxidant activity only at concentration of $0.5 \mathrm{mg} / \mathrm{ml}$ and $0.25 \mathrm{mg} / \mathrm{ml}$.

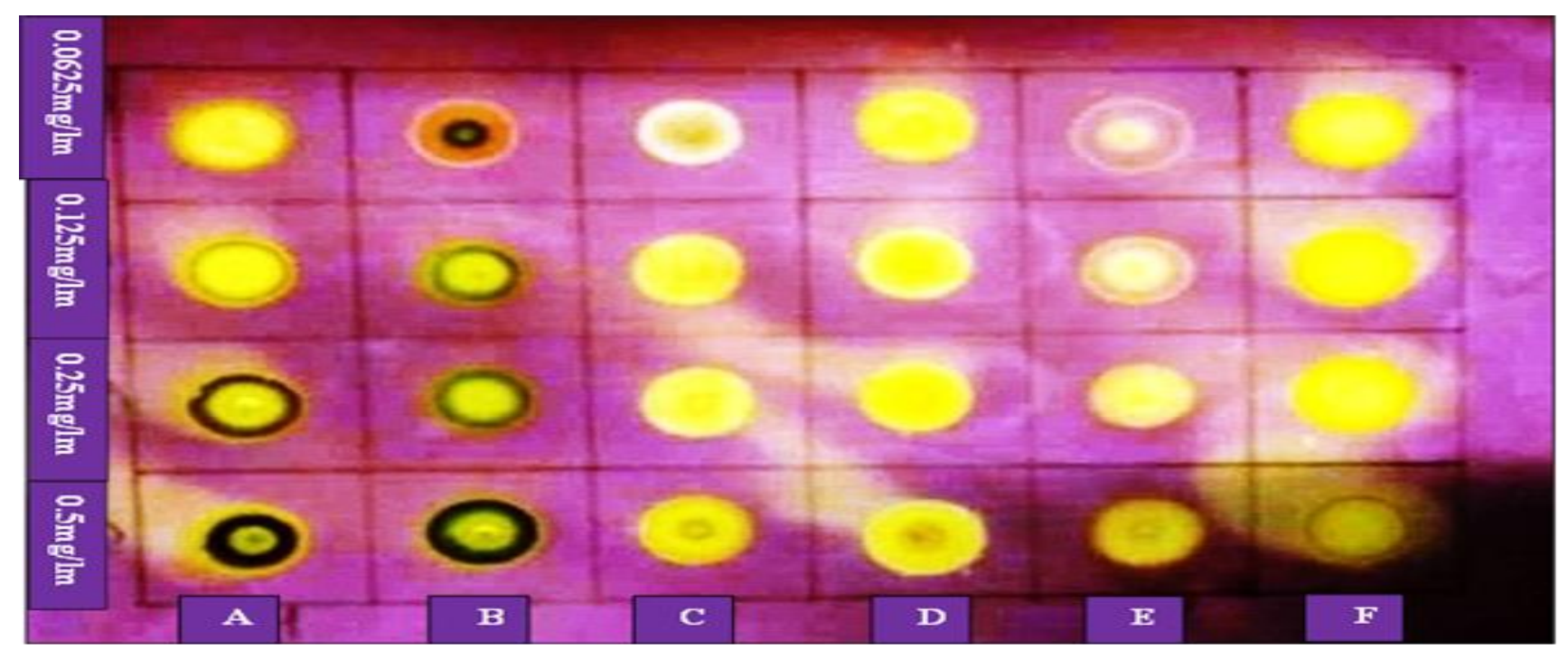

Figure 2: TLC plat of methanol $80 \%$ extract (A) and its fractions; chloroform (B), ethyl acetate (C), n-butanol (D) and water (E), and quercetin (F) on $0.5 \mathrm{mg} / \mathrm{ml}, 0.25 \mathrm{mg} / \mathrm{ml}, 0.125 \mathrm{mg} / \mathrm{ml}$ and $0.0625 \mathrm{mg} / \mathrm{ml}$ stained with DPPH.

\section{DPPH radical scavenging activity assay}

The antioxidant activity of methanol $80 \%$ extract and it's fractions ( chloroform, ethyl acetate, $\mathrm{n}$-butanol) of Boscia arabica leaves was determined. The free radical scavenging activity of $80 \%$ methanol extract and it's fractions was determined (Table 6). Antioxidants activity ranged from $(1.26 \pm 4.20)$ for chloroform fraction to (85.31 \pm 3.12$)$ for $n$-butanol fraction. Ethyl acetate
$(84.30 \pm 2.44)$ and $n$-butanol $(85.31 \pm 3.12)$ are exhibited high free radical scavenging activity when compared with Quercetin (99.10 \pm 4.22$)$.

The percentage (\%) scavenging of DPPH free radical was found to be concentration dependent, i.e. concentration of the extract between $50-200 \mathrm{mcg} / \mathrm{ml}$ greatly increasing the inhibitory activity (Figure 3). Ethyl acetate and $n$ butanol are exhibited high free radical scavenging activity.

Table 6: The DPPH free radical scavenging activity of the methanolic $80 \%$ extract and it's fractions (chloroform, ethyl acetate, n-butanol) of aerial parts of Boscia arabica and Quercetin

\begin{tabular}{|c|c|c|c|c|c|}
\hline \multirow{2}{*}{ Concentration $\mu \mathrm{g} / \mathrm{ml}$} & \multicolumn{5}{|c|}{ Radical scavenging effect (\%) } \\
\cline { 2 - 6 } & Quercetin & $\begin{array}{c}\text { Methanol 80\% } \\
\text { extract }\end{array}$ & $\begin{array}{c}\text { Chloroform } \\
\text { fraction }\end{array}$ & $\begin{array}{c}\text { Ethyl acetate } \\
\text { fraction }\end{array}$ & $\begin{array}{c}\mathrm{n} \text {-Butanol } \\
\text { fraction }\end{array}$ \\
\hline 50 & $93.00 \pm 2.22$ & $14.81 \pm 3.22$ & $1.26 \pm 4.20$ & $45.96 \pm 3.23$ & $62.91 \pm 3.88$ \\
\hline 100 & $98.00 \pm 4.12$ & $33.14 \pm 1.24$ & $3.67 \pm 2.41$ & $68.60 \pm 4.01$ & $83.61 \pm 4.18$ \\
\hline 150 & $98.60 \pm 3.25$ & $46.96 \pm 3.01$ & $7.84 \pm 3.32$ & $83.54 \pm 3.22$ & $85.06 \pm 3.10$ \\
\hline & $99.10 \pm 4.22$ & $60.88 \pm 2.11$ & $16.84 \pm 4.20$ & $84.30 \pm 2.44$ & $85.31 \pm 3.12$ \\
\hline
\end{tabular}




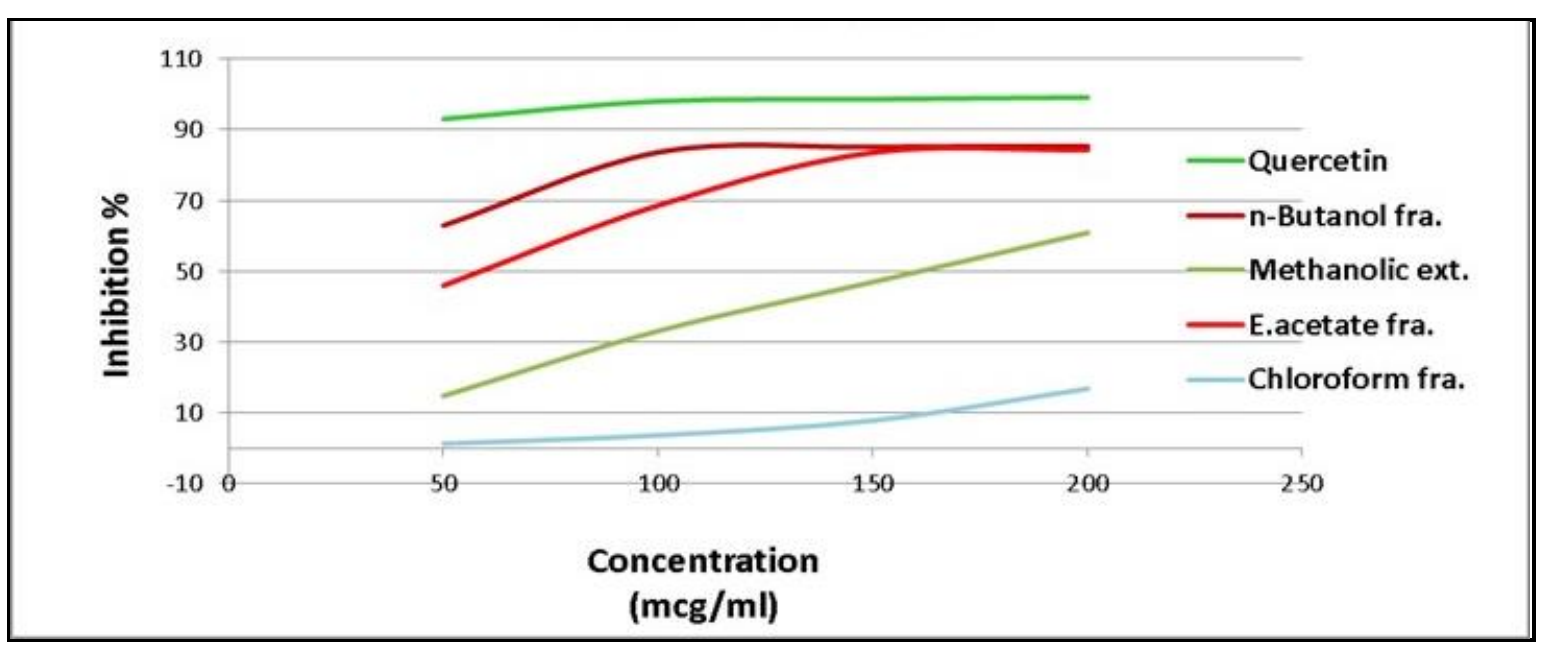

Figure 3: DPPH free radical scavenging activity of methanolic extract it's fractions and Quercetin

\section{CONCLUSIONS}

The present study indicates that the leaves of Boscia arabica (Capparaceae) might serve as important medicinal plant due to the presence of phytochemicals such as carbohydrates, saponins, polyphenols, flavonoids, tannins, triterpenes, sterols and alkaloids, and might give approval to its local usage in the treatment of various diseases. The results of the current study establish the various physicochemical parameters, fluorescence analysis, TLC profile and antioxidant activity of Boscia Arabica, which is endemic to Yemen. This data may help in standardizing the plant as it is an important analytical aspect for evaluating the identity, quality and purity plant drugs. Further deep pharmacognostica and pharmacological investigation is very essential to prove the efficacy of this medicinal herb. More detailed study must be done for further isolation leading to the pure compounds and establishment pharmacological activities of this drug.

Acknowledgement: The authors are grateful to Associate Professor Othman S. Alhawshabi, of the department of Biology, of University of Aden, for his help to identify and authenticated the plant specimen.

\section{REFERENCES}

1. Ingrid H, Hannelore S, Hanne SB. Herbal Medicine in Yemen: Traditional Knowledge and Practice, and Their Value for Today's World, V. 96, Brill, Leiden Boston, 2012, 207.

2. El-Fiky FK, Attif O, Aboul Ela M, Gaanem N. Antimicrobial evaluation of extracts from some Yemeni plants, Alexandrian Journal of Pharmaceutical Sciences, 1995, 9: 3537.

3. Patil VV, Patil RV. Ficus bengalensis Linn- an overview, Int J Pharm Bio Sci., 2010; 1(2): $1-11$.

4. Tatiya A, Surana S, Bhavsar S, Patil D, Patil Y. Pharmacognostic and preliminary phytochemical investigation of Eulophia herbacea Lindl. Tubers (Orchidaceae), Asian Pac J Trop Disease, 2012; 2(Suppl 1): S50-55.

5. Matkowski A, Hajones M, Skalicka-Wozniak K, Slusarczy K. Antioxidant activity of polyphenols from Lycopus lucidus Turcz., Food Chem., 2009; 113: 134- 38.
6. Jain N, Goyal S, Ramawat KG. Evaluation of antioxidant properties and total phenolic content of medicinal plants used in diet therapy during postpartum healthcare in Rajasthan, Int JPharm Pharm Sci., 2011; 3(3): 248-253.

7. Morgan AM, Lim $\mathrm{CH}$ and Kim YH. Lignans, cyclolignans and neolignans from the leaves of Boscia senegalensis (Pers.) Lam. ex Poir., Biochemical Systematics and Ecology, 2015; 59 (22): 226-228.

8. Abdo MA, Othman SS, Salah MI. Ass. Univ. Bull. Environ. Res. October 2012; Vol. 15 (2): 63-81.

9. World Health Organization. Quality Control Methods for Medicinal Plant Materials. WHO Library, Geneva, 1998; 2933.

10. Khandelwal KR. Practical Pharmacognosy techniques and experiments. Nirali Prakashan: Pune, 2006; 157-160.

11. Harborne JB. Phytochemical methods. 3rd edition, Chapman and Hall, London, 1998, p.63.

12. Sass Jl. Elements of Botanical Microtechnique. McGraw Hill Book Co. Inc., New York and London; 1940.

13. Harborne JB. Phytochemical methods: A guide to modern techniques of plant analysis. 3rd edition, Chapman and Hall, London, 2007; 125-175.

14. Evans WC. Trease and Evans Pharmacognosy. 15th edition, WB Saunders, Sydney, Toronto, 2002; 214-252.

15. Waksmundzka-Hajnos $M$, Sherma J and Kowalska T. Thin layer chromatography in phytochemistry. CRC Press, 2008.

16. Wagner $\mathrm{H}$ and Bladt S. Plant Drug Analysis: A Thin Layer Chromatography Atlas. $2^{\text {nd }}$ edition, Springer-Verlag, Berlin, Heidelberg, New York, 1996.

17. Kannan RRR, Arumugam R, Meenakshi S. Thin layer chromatography analysis of antioxidant constituents from seagrasses of Gulf of Mannar Biosphere Reserve, South India, Int J ChemTech Res., 2010; 2: 1526-1530.

18. Braca A, Fico G, Morelli I, De Simone F, Tome F, De Tommasi N. J Ethnopharmacol, 2003; 86: 63-67.

19. Sudhir Sase, et al. International journal of ayurvedic \& herbal medicine, Sep-Oct. 2013; 3 (5): 1343-1346. 
20. Ahmad I, Aqil F, Owais M. Modern phytomedicine: turning medicinal plants into drugs. New York: John Wiley \& Sons, 2006.

21. Swamy P, Mulla SK. Preliminary pharmacognostical and phytochemical evaluation of Portulaca quadrifida Linn., Int J Pharm Tech Res., 2010; 2: 699-702.

22. Patnia S, Saha AN. Physicochemical, phytochemical and elemental analysis of stem bark and roots of Berberis asiatica. Adv Appl Sci Res., 2012; 3: 3624-8.

23. Shwetajain, Sharma $C$, Khatri $P$, Jain $A$, Vaidya $A$. Pharmacognostic and phyto chemical investigations of the leaves of Zizyphus xylopyrus (Retz) wild, Int J Pharm Pharm Sci., 2011; 3: 122-5.

24. Kripa KG, Sangeetha $R$, Chamundeeswari D. Pharmacognostical and physicochemical evaluation of the plant Leucas aspera, Asian J Pharm Clin Res., 2016; 9: 263-8.

25. Duraisankar M, David RA. Identification of Curcuma Longa Rhizomes byPhysicochemical and TLC Fingerprint Analysis, Inter J Pharm Tech Research, 2015; 8 (6): 198-205.

26. Okhale SE, Amanabo MO, Jegede IA, et al. Phytochemical and pharmacognostic investigation of antidiabetic Scoparia dulcis Linn Scrophulariaceae whole plant grown in Nigeria, 2010; 2: 7-16

27. Kokate CK. Textbook of Pharmacognosy. Nirali Prakashan: Pune, 2003; 23: 109-113.

28. Liu KC, Yang SL, Roberts M, et al. Antimalarial activity of Artemisia annua flavonoids from whole plants and cell cultures, Plant Cell Rep., 1992; 11: 637-40.

29. Benedec D, Vlase L, Oniga I, et al. Polyphenolic composition, antioxidant and antibacterial activities for two Romanian subspecies of Achilleadistans Waldst. et Kit. ex Wild. Molecules, 2013; 18: 8725-39.

30. Narender PD, Ganga $R$, et al. Quantification of phytochemical constituents and in vitro antioxidant activity of Mesuaferrea leaves, Asian Pac J Trop Biomed, 2012; 2: S539-42.

31. Vishnu R, Nisha R, Jamuna S, Paulsamy S. Quantification of total phenolics and flavonoids and evaluation of in vitro antioxidant properties of methanolic leaf extract of Tarenna asiatica-an endemic medicinal plant species of Maruthamali hills, Western Ghats, Tami Nadu. J Res Plant Sci., 2013; 204 (2): 196.

32. Amic D, Davidovic-Amic D, Beslo D, Trinajstic N. Structure radical scavenging activity relationships of flavonoids, Croatica Chemica Acta, 2003; 76: 55-61.

33. Diplock AT. Will the "good fairies" please prove to us that vitamin E lessens human degenerative disease, Free Radic Res., 1997; 26 (6): 565-83.

34. Alpinar K, Ozyurek M, et al. Antioxidant capacities of some food plants wildly grown in Ayvalik of Turkey. Food Sci Technol Res, 2009; 15: 59-64.

35. Siama Z, Lalmuansangi C, Zosangzuali M, Tochhawng L, Jagetia GC. Assessment of free radical scavenging activity and antioxidant mediated hepatoprotective effects of Mallotus roxburghianus Muell, In doxorubicin induced oxidative stress in Swiss albino mice, IJPSR, 2018; 9 (10): 4138-4150.

36. Liang $\mathrm{YZ}$, Xie $\mathrm{P}$, Chan K. Quality control of herbal medicines, J. Chromatogr. B, 2004; 812: 53-70.

37. Auddy B, Ferreira M, Blasina F, Lafon L, Arredondo F, Dajas F, Tripathi PC, Seal T, Mukherjee B. Screening of antioxidant activity of three Indian medicinal plants, traditionally used for the management of neurodegenerative diseases, J Ethnopharmocol, 2003; 84 (2-3): 131-8.

38. Blois MS. Antioxidant determinations by the use of stable free radical, Nature, 1958; 181: 1199-1200.

39. Brand-Williams W, Cuvelier ME, Berset C. Use of a free radical method to evaluate antioxidant activity, LWT - Food Science and Technolog, 1995; 28 (1): 25-30.

40. Ali HM, Salem MZM, Al Sahli AA. Performance of Antioxidant Activity of Methanolic Extracts from Different Parts of Some Tree Species using DPPH Radical-scavenging Assay, J. Pure Appl. Microbiol., 2013; 7: 131-137.

41. Soler-Rivas C, Espin JC, Wichers HJ. An Easy and Fast Test to Compare Total Free Radical Scavenger Capacity of Foodstuffs, Phytochemical analysis, 2000; 11 (5): 330-338.

\section{Source of Support: None declared.}

Conflict of Interest: None declared.

For any question relates to this article, please reach us at: editor@globalresearchonline.net New manuscripts for publication can be submitted at: submit@globalresearchonline.net and submit_ijpsrr@rediffmail.com 